\section{"LOWER HALF HEADACHE" (NEURALGIC) OF NASAL ORIGIN}

GLOSSODYNIA, OTALGIA, NAUSEA, PARAGEUSIA, VERTIGO, SCOTOMA, PHOTOPHOBIA, RHINORRHEA

AND ASTHMA AS ISOLATED RELATED PHENOMENA *

GREENFIELD SLUDER, M.D. ST. LOUIS

In $1908 \mathrm{I}^{1}$ described a "lower half headache" (neu1algic) which seemed to be related to the nasal (sphenopalatine or Meckel's) ganglion. In those cases, there was almost always a recognizable lesion in the district in which the ganglion lay, and the symptoms could be relieved by cocainization of the ganglion. Later, I found that typical lower half headache could be present without such a lesion and could not be relieved by such treatment. These were cases of sphenoiditis, hyperplastic or suppurative and I believed that the headache was produced by irritation or inflammation of the nerves which supply the ganglion. Such lesions, of course, are situated central to the ganglion and naturally are not influenced by cocainization of it. Treatment of the sphenoid is successful for these lesions.

\section{CLINICAL PICTURE OF LOWER HALF HEADACHE}

This "lower half headache" when complete consists of pain about the eye, the upper jaw and the teeth, extending to the zygoma and temple, with earache and pain in the mastoid, emphasized at a point $5 \mathrm{~cm}$. behind it. This point is always tender on pressure, although the pain is often temporarily absent. Thence, it extends to the occiput, neck, shoulder, scapula, arm, forearm, hand and fingers. This is the pain, or neuralgic, syndrome. There may, however, be added to this a sympathetic syndrome of sneezing, rhinorrhea, lacrimation and photophobia. The sense of taste is usually slightly diminished on the anterior half of the tongue, and occasionally there may be parageusia or vertigo. There may be slight motor and sensory disturbances in the soft palate, which are clinically negligible save for an imperfect opening of the eustachian tube in swallowing.

Such is the ordinary or routine syndrome. These postnasal lesions - ganglion or sphenoid-do not always produce the ordinary syndrome. Not infrequently they produce ophthalmic migraine, sometimes complete, that is, the attack begins with scotoma or hemiopia, then headache, nausea or vomiting, aphasia and, finally, hemiparesis. Ophthalmic migraine is definitely cyclic. The aphasia and hemiparesis, however, are rarely present.

More rarely such postnasal lesions produce "lower half headache," accompanied by nodules in the scalp and nape of the neck, which sometimes disappear after the attack and sometimes remain for a longer period. In these cases of "nodular headache," it has been thought that the nodules produced the headache.

\section{ISOLATED PHENOMENA}

Were each of these clinical pictures always complete there should be little difficulty in referring them to their origin. This, however, is rarely true. Many of the symptoms are usually present; but there is a small

* Read at the meeting of the Tri-State District Medical Association, Peoria, Ill., Oct. 31, 1922.

1. Sluder, Greenfield: The Roile of the Sphenopalatine (Meckel's) Ganglion in Nasal Headache, New York M. J. May 23, 1908. percentage of cases in which only isolated symptoms are present. As this fact becomes better known, probably the number of cases reported will be larger. The cases presenting only isolated symptoms are obviously the most obscure. They are encountered in all departments of practice and give rise to much difficulty not only for the patient but also for the physician.

They are probably met least often by the rhinologist because there are no symptoms to direct attention to the nose.

The cases of isolated symptoms of nausea, vertigo and the like, referable to the postnasal district as the etiologic factor, in my experience, were first recognized in cases in which a well defined "lower half headache" had been present for some time before and had brought the patient to my care. In these patients there was an absence, at those times, of all other symptoms of the "lower half headache" which had become so well known both to the patient and to me. In the nasal ganglion cases, they were relieved by cocainization of the ganglion, and in the sphenoidal cases, by intrasphenoidal cocainization. Later I learned that such symptoms could be constantly the only manifestation of the postnasal lesion.

In connection with a mention of isolated phenomena related to the "lower half headache" of nasal origin, it is of interest to cite some other phenomena that are controllable from the postnasal district but which at present cannot be recognized as in any way associated with "lower half headache." Conspicuous and most interesting, in this class, is glossodynia. At the meeting of the Southern Medical Association, Nov. 17, 1921, Dr. L. W. Dean reported that glossodynia could be controlled by cocainization of the nasal ganglion, and that permanent relief was obtained by alcohol-phenol injection of the ganglion. I have since verified Dr. Dean's observation in four cases of glossodynia of years' standing that had resisted all treatment by the most sagacious physicians, besides my futile efforts. These patients had never had "lower half headache." Any one who has ever had to do with glossodynia, not only patient but physician as well, will welcome this possible relief. In my experience, nothing has been more resistant to all treatment than glossodynia. The mental relief is as great a comfort to the patient as the cessation of physical pain. Such patients almost always believe they have cancer of the tongue, despite the assurances of the physician to the contrary.

At the meeting just referred to, I reported the observation that earache of inflammatory middle ear origin could be controlled by cocainization of the nasal ganglion. I have not, however, had a sufficient number of such cases to state how often this may be true. At the same time, I reported that pain in the lower jaw, after the difficult removal of teeth, could be controlled by cocainization of the nasal ganglion; but I do not know with what regularity. Dr. W. V. Mullin of Colorado Springs had a patient with trigeminal neuralgia with much pain in the lower jaw. He controlled the pain by cocainization of the nasal ganglion." Reflex earache after tonsillectomy may also be controlled in this way.

Nausea is encountered in all lines of practice and may be obscure in origin. Physical pain when severe may cause nausea, and I believed this to be the explanation of it in "lower half headache." A few years ago, however, I learned that it could be an

2. Personal communication to the author. 
isolated phenomenon in postnasal lesions. I have seen purposeless vomiting continue for twelve hours, and stop five minutes after cocain was set for anesthesia of the nasal ganglion. This happened in a case of severe "lower half headache" of nasal ganglion origin which could be controlled from the ganglion. On this occasion, however, there was no headache. The previous association led me to experiment with cocainization. Since then, I have found that it is not infrequent that patients with postnasal lesions complain only of more or less slight nausea; but sometimes they complain emphatically.

Paragetisia is occasionally encountered in "lower half headache." I have from time to time heard it described as an unpleasant metallic taste. Usually, it is clinically negligible. On one occasion, however, I found it as an isolated symptom. In this case the patient complained of a constant bad taste in her mouth that spoiled her appetite and often led to nausea. She complained very much of not being able to eat because of it. She had lost 10 pounds ( $4 \mathrm{~kg}$.) in weight. She had a well marked hyperplastic postethmoid sphenoiditis without secretion. Cocainization of the nasal ganglion, repeated six times, stopped the bad taste. Not infrequently patients complain of a bad tasting secretion or pus descending from the nose into the pharynx. In this case, satisfactory and prolonged observation eliminated this possibility.

Vertigo is a symptom frequently met in "lower half headache." It is usually described by the patients as a sensation of shifting of the earth from side to side under them. Rarely is it described as a rising or falling sensation. Never, that I recall, has it been described as a rotatory sensation. Occasionally it has been experienced only in the recumbent posture. I have met vertigo as an isolated symptom-not so infrequently. On one occasion a sphenoiditis had produced a choroiditis without headache. The degree of vertigo was such that the patient had to be supported by two men in order to walk. On opening the postethmoid sphenoid district, the vertigo ceased. The patient immediately stood up and walked alone. It is not the most infrequent of the isolated symptoms of the postnasal lesion.

Otalgia is common in the "lower half headache" and not at all uncommon as an isolated symptom. I have seen it many times, but it was Lillie $^{3}$ who depicted the disasters to which it may lead. $\mathrm{He}$ reported mastoid and middle ear surgery that had been performed in vain for otalgia, which was afterward controlled from the nasal ganglion.

Scotoma is an almost constant symptom in ophthalmic migraine, which, in turn, is very often of postnasal origin. I have seen it remain as an isolated symptom in cases of nasal ganglion origin after the ganglion had been injected, with relief of all other symptoms. The scotoma would appear from time to time, and the patient would recognize it as the aura of the attack; but the other symptoms would not follow. I have at times had patients with postnasal lesions who complained only of transitory blindness, and I concluded that it was the isolated scotoma of ophthalmic migraine. Postnasal therapy has relieved these patients.

Photophobia is common and often of high grade in the sympathetic syndrome of the postnasal lesion. I

3. Lillie, H. I.: Otalgia and Mastoidalgia Not Indications for Oper ation on the Mastoid Process: Report of Three Cases, J. A: M. A. 79: 431 (Aug. 5) 1922 . have found it to be an isolated symptom. On one occasion it was unilateral and of nasal ganglion origin. Injection of the ganglion relieved it.

Rhinorrhea is common in rhinologic practice as an isolated phenomenon of the postnasal lesion. Often, however, it has a complement of low-grade headache. Usually it can be controlled by injecting the ganglion. More rarely it is of sphenoidal origin.

Asthma occurs with postnasal lesions, sometimes with "lower half headache" and often without it." Treatment of the postnasal lesion often relieves these patients.

In these observations, all possible precaution has been taken to exclude collateral possibilities as etiologic factors. Confusion may arise from the psychic effect of cocain. It was applied to other parts of the nose in the effort to ascertain what might be its influence. Answers by the patients in the beginning were sometimes confusing, but when the cases were severe and the experiment repeated several times the replies were conclusive. Diagnosis of the postnasal lesion has been given in detail elsewhere. ${ }^{5}$

\section{BALANCING THE DIABETIC DIET *}

\section{SOLOMON STROUSE, M.D. CHICAGO}

The present interest in properly balancing the diabetic diet, stimulated particularly by the researches of Shaffer, ${ }^{1}$ Newburgh and Marsh, ${ }^{2}$ Woodyatt, ${ }^{3}$ Wilder ${ }^{4}$ and others, has led to efforts to work out a simple method of determining the food proportions required by any diabetic patient. As a working basis for treating diabetics, we may assume:

1. The patient's basal caloric requirements should be met.

2. Nitrogen balance can be maintained if the protein content of the diabetic diet is approximately $0.66 \mathrm{gm}$. per kilogram of body weight, provided sufficient carbohydrate and fat are burned to meet caloric requirements.

3 . The glucose value of the diet consists of total carbohydrate intake plus 58 per cent. of protein intake, provided the patient is in nitrogen equilibrium.

4. The ratio of fat to glucose must be below the point at which a clinically significant ketosis appears.

The object of a balanced diet is to furnish sufficient calories to maintain a patient in nitrogen equilibrium without glycosuria or ketonuria. When the patient is not in nitrogen equilibrium, he is burning body protein and producing glucose from the glucose fraction of protein. The total basal caloric requirement may be established in several ways. Either the basal metabolism can be determined directly, or it can be figured from the Du Bois scale for height and weight. Persons suffering from severe diabetes with low glucose tolerance will be compelled to limit their activities

4. Sluder, Greenfield: Asthma as Nasal Reflex, J. A. M. A. 73: 589 (Aug. 23) 1919.

5. Sluder, Greentield: Headaches and Eye Disorders of Nasal Origin, t. Louis, C.' V. Mosby Company, 1918

* From the medical clinic and the Nelson Morris Memorial Institute Medical Research of the Michael Reese Hospital.

1. Shaeffer, P. A.: J. Biol. Chem. 46: 98 (March) 1921

2. Newburgh, L. H., and Marsh, P. L.: Use of a High Fat Diet in Treatment of Diabetes Mellitus, Arch. Int. Med. 26: 647 (Dec.) 1920. Marsh, P. L.; Newburgh, L. H., and Holly, L. E.: Nitrogen Require ment for Maintenance in Diabetes Mellitus, ibid. 29: 97 (Jan.) 1922. 3. Woodyatt, R. T.: Objects and Method of Diet Adjustment in Diaetes, Arch. Int. Med. 28: 125 (Aug.) 1921. 4. Wilder, R. M., and Winter, M. D.: J. Biol. Chem. 52: 393
(June) 1922. 